\title{
Kaufman Domains of Creativity Scale: Relationship to Occupation and Measurement Invariance across Gender
}

\author{
Kirill G. Miroshnik ${ }^{\mathrm{a}}$, Olga V. Shcherbakova ${ }^{\mathrm{a}}$, and James C. Kaufman ${ }^{\mathrm{b}}$ \\ ${ }^{a}$ Faculty of Psychology, Saint Petersburg State University \\ ${ }^{b}$ Department of Educational Psychology, University of Connecticut
}

\begin{abstract}
Author Note
Kirill G. Miroshnik (iD https://orcid.org/0000-0001-9855-1123

Olga V. Shcherbakova (D) https://orcid.org/0000-0002-9200-4310

James C. Kaufman (iD https://orcid.org/0000-0003-0595-2820
\end{abstract}

We have no conflicts of interest to disclose. The data files are available at Open Science Framework: https://osf.io/g5bk4/.

We wish to acknowledge the help provided by Daria Makarova with back-translation and Iana Bashmakova with the coding of data on occupations.

Correspondence concerning this article should be addressed to Kirill G. Miroshnik, Faculty of Psychology, Saint Petersburg State University, Makarova emb. 6, Saint Petersburg, 199034, Russian Federation. E-mail: cyril.miroshnik@gmail.com. 


\begin{abstract}
Kaufman Domains of Creativity Scale (K-DOCS) is a self-report of creative behavior in five distinct domains. The present study aims to translate K-DOCS into Russian and evaluate its psychometric properties. The psychometric analysis was performed on a sample of adults recruited through Yandex Toloka $\left(N=1011 ; M_{\text {age }}=35.94, S D_{\text {age }}=10.95\right)$ from various regions of Russia and Commonwealth of Independent States (CIS) countries. Exploratory and confirmatory factor analyses indicated that the model with five correlated factors showed the best fit to empirical data. All factors demonstrated good internal consistency and moderate test-retest reliability. The correlation and hierarchical regression analyses for K-DOCS factors, creative achievements by CBI (Creative Behavior Inventory), and personality traits by BFI-2 (Big Five Inventory - 2) yielded evidence for an adequate level of convergent and discriminant validity. We also examined differences across K-DOCS factors among occupations defined by Holland's typology and attempted to investigate K-DOCS measurement invariance across gender. As a result, we obtained evidence supporting the construct validity of K-DOCS and established its partial measurement invariance across gender. The current study shows that Russian K-DOCS has satisfactory psychometric properties and can serve as a trusted guide into various manifestations of humans' creative behavior.
\end{abstract}

Keywords: creativity, creativity domains, self-assessment, Holland's occupational types, measurement invariance. 


\section{Kaufman Domains of Creativity Scale: Relationship to Occupation and Measurement Invariance across Gender}

A common approach to creativity measurement focuses on self-assessments of creative behavior (Silvia, Wigert, Reiter-Palmon, \& Kaufman, 2012; Snyder, Hammond, Grohman, \& Katz-Buonincontro, 2019). Although self-assessments are more prone to subjective biases than actual creative performance, they provide useful information about people's beliefs and perceptions regarding their creativity (Kaufman, 2019). However, to gain insights into creative self-perceptions, researchers should base their studies on psychometrically solid instruments.

The Kaufman Domains of Creativity Scale (K-DOCS; Kaufman, 2012) is a widely used self-report measure of creative behavior. Its theoretical premises are derived from the Amusement Park Theoretical model of creativity (APT; Baer \& Kaufman, 2005, 2017). According to the APT, creative product results from the interaction of initial requirements (such as intelligence, motivation, and environment) and the domain, which is hierarchically represented by general thematic areas (e.g., science), specific domains (e.g., biology), and micro-domains (e.g., biophysics). Further, K-DOCS focuses on everyday creativity and thus provides an opportunity to examine creativity-related activities across varied populations while avoiding bias toward eminent creativity (see Glăveanu, 2014).

The initial validation uncovered the five-factor structure of K-DOCS, with each factor showing appropriate internal consistency and test-retest reliability as well as preliminary support for construct validity (Kaufman, 2012; see also McKay, Karwowski, \& Kaufman, 2017). The K-DOCS factors are Everyday (creative activities in everyday life), Scholarly (intellectual and verbal creativity), Performance (creativity in literature and music), Scientific (creativity in mechanics and mathematics), and Artistic (creativity in visual arts). Further research conducted in China (Tu \& Fan, 2015), Czech Republic (Dostál, Plháková, \& 
Záškodná, 2017), Malaysia (Tan, Tan, Cheng, Hashim, \& Ong, 2019), Nigeria (Awofala \& Fatade, 2015), Poland (McKay et al., 2017), and Turkey (Kandemir \& Kaufman, 2019; Şahin, 2016) not only largely confirmed previous results but also extended them.

The present study aims to expand the empirical evidence on psychometric properties of K-DOCS by validating a Russian version of the measure. In particular, we focus on five research objectives. First, we aim to resolve an inconsistency in results on the factor structure of K-DOCS. Previous studies - relying on Kaiser-Guttman rule and scree test-have established a five-factor structure (e.g., Dostál et al., 2017; McKay et al., 2017; Şahin, 2016), yet recent evidence from a Turkish adaptation — based on the application of a more robust and advanced technique of parallel analysis - have inclined towards a nine-factor structure (Kandemir \& Kaufman, 2019; see also Kapoor, Reiter-Palmon, \& Kaufman, 2020). We suggest that the analysis of 50 items from K-DOCS on a large sample of 1,260 participants could have led to a more fine-grained factor structure because the parallel analysis is prone to overestimate the number of factors to retain in case of a large number of observed variables (Van der Eijk \& Rose, 2015) and large sample sizes (Warne \& Larsen, 2014). Supplementing parallel analysis with other recommended methods may lead to different results. Hence, in line with earlier evidence, we hypothesize the following:

Hypothesis 1 (H1). A model with five correlated factors will provide the best description of empirical data for K-DOCS.

Second, although internal consistency reliability has been reported in every study of K-DOCS, not so many studies have examined its test-retest reliability (Awofala \& Fatade, 2015; Kaufman, 2012). For research purposes, we consider values of .70 and higher indicating satisfactory reliability. Thus, we hypothesize the following: 
Hypothesis 2 (H2): Total scores for each K-DOCS factor will demonstrate satisfactory test-retest reliability $(>.70)$.

Third, we are concerned with demonstrating further support for the construct validity of K-DOCS, including convergent and discriminant validity. Convergent validity refers to an examination of consistency in results obtained on a target measure and other conceptually close measures. For this purpose, we have chosen a short version of Creative Behavior Inventory (CBI; Dollinger, 2003). Hypotheses have been formulated with regards to different subscales rather than a total score because the Russian CBI showed a good fit to a model with several first-order factors and one second-order factor (Lebedeva \& Bushina, 2015; Lebedeva, Schwartz, Van de Vijver, Plucker, \& Bushina, 2019), which stands in contrast to evidence favoring one-factor solution1 (Dollinger, 2003; Silvia et al., 2012). Thus, we put forward the following hypotheses:

Hypothesis $3 a(\mathrm{H} 3 a)$ : Artistic factor of K-DOCS will have moderate positive correlations with CBI Crafts and Visual arts.

Hypothesis $3 b(\mathrm{H} 3 \mathrm{~b})$ : Performance factor of K-DOCS will have a moderate positive correlation with CBI Literature.

To lend additional support for convergent validity, we planned to analyze the relationship between K-DOCS factors and Big Five personality traits. For convergent validity, openness to experience is the most relevant trait because numerous studies identified it as one of the central characteristics of creative personality (Jauk, Benedek, \& Neubauer, 2014; Kaufman et al., 2016; Silvia, Kaufman, \& Pretz, 2009). Openness to experience

\footnotetext{
${ }_{1}$ We also limited our focus to three instead of six subscales of CBI because we failed to communicate with the authors of original adaptation to receive a full version of the questionnaire. In this situation, we retrieved only 11 items translated to Russian that have been available from Lebedeva and Bushina (2015).
} 
encompasses two moderately related subdimensions_-openness and intellect (DeYoung, Quilty, \& Peterson, 2007; see also Christensen, Cotter, \& Silvia, 2019). Openness reflects aspiration for gaining unusual sensory and aesthetic experience, while intellect reflects aspiration for gaining intellectual information and thriving for learning and thinking over new abstract concepts and ideas. Recently, it was found that openness-independently of intellect—predicts creative achievements in arts but not sciences, whereas intellect— independently of openness_-predicts creative achievements in sciences but not arts (Kaufman, 2013; Kaufman et al., 2016). Although results of previous studies are grounded in real-life creative accomplishments, it has not been established yet if comparable results could be obtained for self-reported creativity scales. Therefore, we address this issue and predict the following:

Hypothesis 3c (H3c): Artistic factor of K-DOCS will have a moderate positive correlation with openness.

Hypothesis $3 d(H 3 d)$ : Scholarly factor of K-DOCS will have a moderate positive correlation with intellect.

Discriminant validity implies that measures of different constructs should not be highly related unless a theory predicts so. To assess discriminant validity, we have made predictions on the relation of K-DOCS factors to Big Five personality traits. Based on the results of previous studies, we have no reason to propose high or even moderate associations between Big Five personality traits—except openness to experience — and self-assessments in science and visual arts. A more complex picture emerges for everyday creativity and performative arts. Creativity in daily life, which embraces an aspect of interpersonal communication, has been moderately linked to extraversion and agreeableness (Kaufman, 2012; McKay et al., 2017) but no other traits. In the domain of performative arts, which 
encompass subdomains of music, literature, and acting, higher expression of creativity corresponds to a higher level of extraversion (Kaufman, 2012; Silvia et al., 2009) but no other traits. Hence, we formulate the following hypotheses:

Hypothesis $4 a(\mathrm{H} 4 \mathrm{a})$ : Artistic, Scholarly, and Scientific factors of K-DOCS will be weakly correlated with all personality traits except for openness to experience.

Hypothesis $4 b(H 4 b)$ : Scientific factor of K-DOCS will be positively correlated with agreeableness, while Artistic factor will be negatively correlated with agreeableness. Hypothesis 4c (H4c): Everyday factor of K-DOCS will be weakly correlated with conscientiousness and neuroticism.

Hypothesis $4 d(H 4 d)$ : Performance factor of K-DOCS will be weakly associated with conscientiousness, agreeableness, and neuroticism.

Hypothesis $4 e$ (H4e): Performance factor of K-DOCS will be positively related to extraversion.

Fourth, valuable information about construct validity can be gathered by juxtaposing results on the target measure with external criteria. Inasmuch as studies on creativity are predominantly conducted on samples of university students (see Glăveanu, 2014), researchers often sought to identify the relationship between various aspects of creative potential and students' majors (Silvia \& Nusbaum, 2011). For example, Kandemir and Kaufman (2019) compared students' self-ratings on domains of K-DOCS among their majors. They found that science and math majors had higher self-ratings regarding Scientific factor, whereas arts majors rated themselves higher on Performance and Artistic factors. Briefly, established trends lie in agreement with the general logic of the K-DOCS and support its constructive validity. 
In the current study, we intend to figure out whether previous evidence on the construct validity of K-DOCS is generalizable to the adult population. To achieve our aim, we plan to compare creativity self-ratings in various domains against professional occupations outlined in Holland's model (RIASEC; Holland, 1985): realistic (e.g., engineer), investigative (e.g., biochemist), artistic (e.g., artist), social (e.g., teacher), enterprising (e.g., economist), and conventional (e.g., accountant). Holland's RIASEC model has been already implemented to determine how various occupations are linked to personality traits and creative self-beliefs (Kaufman, Pumaccahua, \& Holt, 2013) as well as creative problemsolving preferences (Puccio, Miller, \& Acar, 2019). By matching occupational types and creativity domains, we put forward the following hypotheses:

Hypothesis $5 a(H 5 a)$ : Investigative types will score higher on K-DOCS Scholarly and Scientific factors when compared to other types, while realistic type will have higher scores only in Scientific factor.

Hypothesis $5 b(\mathrm{H} 5 b)$ : Artistic types will score higher on K-DOCS Performance and Artistic factors in comparison to other types.

Hypothesis 5c $(\mathrm{H} 5 \mathrm{c})$ : Social types will score higher on Everyday factor of K-DOCS than other occupational types.

Finally, we also want to establish measurement invariance of K-DOCS across gender and investigate gender differences in self-assessment of creativity across domains. Kandemir and Kaufman (2019) intended to shed light on gender differences applying K-DOCS but failed due to disconfirmation of full measurement invariance. Conversely, a statistical analysis performed later on a larger sample of American people $(N=22,031)$ established gender invariance of K-DOCS for both five- and nine-factor models (Kapoor et al., 2020). Some gender differences on creativity across different domains have been found in previous 
studies. For instance, Kaufman (2006) collected data on creative self-perceptions in 56 domains on a sample of 3,553 students and community members and found that females reported higher creativity ratings on social communications and visual arts, whereas males reported higher creativity ratings on science and sports. Along the same line, Kaufman et al. (2010) and Werner, Tang, Kruse, Kaufman, and Spörrle (2014) observed that female students rated their creativity higher in arts while male students rated their creativity higher in math and science (see also Diedrich et al., 2018). Taking into account the described trends, we hypothesize the following:

Hypothesis $6 a(H 6 a)$ : Females will score higher than males on Performance and Artistic factors of K-DOCS.

Hypothesis $6 b(H 6 b)$ : Males will score higher than females on Scientific factor of KDOCS.

\section{Method}

\section{Power analysis}

We performed a Monte-Carlo power analysis to determine the sample size needed for factor analysis. The analysis was conducted in $\mathrm{R}$ version 3.5.2 using packages lavaan (Rosseel, 2012) and simsem (Pornprasertmanit, Miller, \& Schoemann, 2013). We defined a population model based on the results of previous studies, varied the sample size from 300 to 600 , and evaluated simulation results by criteria outlined in Muthén and Muthén (2002). As a result, the minimal sample size was determined as 450 . Since we planned to do both exploratory and confirmatory factor analyses, the minimal sample size had to be doubled. Besides, the sample size of 900 provided adequate statistical power for examining convergent 
and discriminant validity. The $\mathrm{R}$ code for the simulation is available via the Open Science Framework (OSF; https://osf.io/g5bk4/?view_only=6d1905355d6d429a8be399e0784b7756).

\section{Control for inattentive respondents}

We intended to recruit participants on Yandex Toloka, which is a Russian analog for Amazon MTurk, and thus needed to control for careless responding (e.g., McKibben \& Silvia, 2017). According to Fleischer, Mead, and Huang (2015), a proportion of inattentive respondents can amount to up to $42 \%$ in online samples. Taking $42 \%$ as a reference point, we redefined a minimal sample size as $N=1278(900 \times 1.42=1278)$. Inattentive respondents were identified with a priori and post-hoc methods (Niessen, Meijer, \& Tendeiro, 2016). A priori methods included an instructed response item, whereas post-hoc methods incorporated response time, maximum longstring, and Mahalanobis distance (Dupuis, Meier, \& Cuneo, 2019; Meade \& Craig, 2012; Niessen et al., 2016). The detailed description of how each method was applied can be accessed via OSF (https://osf.io/g5bk4/?view_only=6d1905355d6d429a8be399e0784b7756).

\section{Participants}

We gathered data from 1313 users of Yandex Toloka and compensated \$0.24 per person for their participation. However, 302 responses were discarded due to several reasons: double submissions $(n=37)$, data not from Russia or CIS countries (Commonwealth of Independent States; $n=2)$, and data from inattentive respondents $(n=263)$. The final sample consisted of 1011 participants (549 females) aged from 18 to $70(M=35.94, \mathrm{~S} D=10.95)$ located in 315 towns and villages of Russia (82.4\%), Ukraine (14.1\%), Belarus (3.2\%), Uzbekistan $(0.2 \%)$, and Kazakhstan $(0.1 \%)$. The raw data is available via OSF 
(https://osf.io/g5bk4/?view_only=6d1905355d6d429a8be399e0784b7756). The research project was approved by the Ethics Committee of Saint Petersburg State University.

A smaller group of participants took part in the test-retest procedure for K-DOCS. We shared the link to a Google Form with all who agreed to proceed with test-retest $(N=602)$. As a result, we received responses from 168 people $(27.9 \%$ from $N=602)$ during a period from 14 to 33 days $(M=14.75, S D=2.03)$ after the main study. We excluded duplicates $(n=$ 4), data of unidentified ( $n=2)$ and inattentive respondents (by post-hoc methods; $n=24$ ), and all responses that came later than 21 days $(n=8)$ since the main study. Therefore, testretest was carried out on a reduced sample of 130 participants ( 72 females; from 18 to 69 years, $\left.M_{\text {age }}=36.89, S D_{\text {age }}=11.18\right)$. All participants received detailed individual feedback about the results of the assessment.

\section{Measures}

Kaufman Domains of Creativity Scale. The Kaufman Domains of Creativity Scale (K-DOCS; Kaufman, 2012) was administered as a self-report measure of creative behavior in five broad domains: Everyday (e.g., "thinking of new ways to help people"), Scholarly (e.g., "analyzing the themes in a good book"), Performance (e.g., "making up rhymes"), Scientific (e.g., "solving math puzzles"), and Artistic (e.g., "appreciating a beautiful painting"). The participants were instructed to rate their creativity on a 5-point Likert scale $(1=$ much less creative, $5=$ much more creative), comparing themselves to people about their age and life experiences.

For the translation of K-DOCS to Russian, we used a procedure of back-translation with a monolingual test (Maneesriwongul \& Dixon, 2004). First, two Russian-speaking researchers fluent in English (first two authors) independently translated all items to Russian. Then two versions of translation were compared and integrated into one. Next, the qualified 
translator performed a backward translation. After that, the back-translated version was checked against the original K-DOCS by two English-speaking researchers. All differences between Russian and English versions were corrected during the second round of backtranslation. Finally, the revised version was piloted on a sample of ten Master's students aged 21-23 (Russian monolinguals; $100 \%$ females). As a result, minor changes were introduced to the wordings of instruction and three items.

Creative Behavior Inventory. The short version of Creative Behavior Inventory (CBI; Dollinger, 2003) was employed to assess participants' involvement in various creative activities within the last year. The participants had to rate their engagement in creative behavior on a 4-point scale $(1=$ never did this, $2=$ did this once or twice, $3=$ did this $3-5$ times, $4=$ did this more than 5 times). As mentioned earlier, we limited our focus to the Russian-translated items that were provided in Lebedeva and Bushina (2015). The chosen subset of items covered domains of Crafts (e.g., "made a ceramic craft"), Visual arts (e.g., “painted an original picture"), and Literature (e.g., "wrote a short story”). All subscales demonstrated satisfactory internal consistency reliability: $\omega_{t}=.60$ (for Crafts), $\omega_{t}=.87$ (for Visual arts), and $\omega_{\mathrm{t}}=.69$ (for Literature).

Big Five Inventory-2. The Big Five Inventory-2 (BFI-2; Soto \& John, 2017) was used to measure the Big Five personality domains and their facets. The participants responded to 60 items (e.g., "I am someone who is full of energy") using a 5-point Likert scale $(1=$ disagree strongly, 5 = agree strongly $)$. Shchebetenko, Kalugin, Mishkevich, Soto, and John (2020) demonstrated evidence for reliability, construct validity, and measurement invariance across age and sex for domains and facets of the Russian BFI-2. Internal consistency reliability for each personality domain was as following: $\omega_{\mathrm{t}}=.85$ (for Extraversion), $\omega_{\mathrm{t}}=.78$ (for Agreeableness), $\omega_{\mathrm{t}}=.83$ (for Conscientiousness), $\omega_{\mathrm{t}}=.81$ (for Openness to Experience), and $\omega_{\mathrm{t}}=.87$ (for Neuroticism). 


\section{Procedure}

Data was collected via Yandex Toloka. First, participants read the informed consent and clicked a button confirming they understood its content. Then they completed all creativity measures in the following order: K-DOCS, CBI, and BFI-2. The order of items for K-DOCS and CBI was randomized because these measures did not have a predetermined order of items. Finally, participants provided information on their age, gender, and occupation and could leave their emails to take part in the test-retest procedure. We had no intention to set time limits for completion, but Yandex Toloka required doing so. The time allowed was restricted to 45 minutes per person. After two weeks, we contacted all participants who agreed to proceed with the test-retest and shared a link to Google Form that led to the K-DOCS measure. Again, the order of K-DOCS items was randomized. No time constraints were imposed.

\section{Data analysis}

Statistical analysis was performed using SPSS version 25 and $\mathrm{R}$ version 3.6.1. The $\mathrm{R}$ code used for analysis is available via OSF (https://osf.io/g5bk4/?view_only=6d1905355d6d429a8be399e0784b7756).

First, exploratory (EFA) and confirmatory factor analysis (CFA) were conducted to determine the dimensionality of K-DOCS (packages psych, GPArotation, lavaan; Bernaards \& Jennrich, 2005; Revelle, 2019; Rosseel, 2012). We randomly split the sample into two halves to perform EFA and CFA on independent samples. The EFA sample consisted of 505 participants $\left(55.4 \%\right.$ females; $18-69$ years, $\left.M_{\text {age }}=35.93, S D_{\text {age }}=10.94\right)$ whereas the CFA sample consisted of 506 participants $\left(53.2 \%\right.$ females; $18-70$ years, $M_{\text {age }}=35.94, S D_{\text {age }}=$ 
10.95). To examine multivariate normality and identify the number of factors to extract in the EFA, we used additional packages such as MVN, EFA.MRFA, and RGenData (Korkmaz, Goksuluk, \& Zararsiz, 2014; Lorenzo-Seva, Timmerman, \& Kiers, 2011; Ruscio \& Roche, 2012). For CFA analysis, global indices of $\chi^{2}$, CFI, SRMR, and RMSEA with $90 \%$ confidence intervals were used to estimate model fit. The following values were considered acceptable: $\chi^{2}(p>.05)$, CFI $(\geq .90)$, RMSEA $(\approx .06,90 \% \mathrm{CI} \leq .08)$, and SRMR $(\approx .08)$. However, predefined cut-off values should be regarded as useful orienteers rather than strict criteria for making a dichotomous decision for either acceptance or rejection of a model (Markland, 2005; Marsh, Hau, \& Wen, 2004).

Second, internal consistency and test-retest reliability for K-DOCS factors were estimated by omega total and intra-class correlation coefficient (ICC; packages psych and MBESS; Kelley, 2018), respectively. We did not resort to calculating Cronbach's alpha because modern psychometrics accumulated sufficient evidence confirming serious limitations of the latter (e.g., McNeish, 2018; Sijtsma, 2009). In addition to providing reliability value, $95 \%$ confidence intervals associated with it were also calculated using the BCa method (bias-corrected-and-accelerated; Kelley \& Pornprasertmanit, 2016). We used $\operatorname{ICC}(\mathrm{A}, 1)$ to assess test-retest reliability because it shows the absolute degree of measurement agreement (Qin, Nelson, McLeod, Eremenco, \& Coons, 2019) in contrast to the Pearson correlation coefficient that reflects only the degree of measurement consistency (Zaki, Bulgiba, Nordin, \& Ismail, 2013).

Further, hypotheses about convergent and divergent validity were explored by Pearson correlation coefficients with Holm's adjustment and hierarchical regression analysis. Data comparison on five domains of K-DOCS across RIASEC occupations was performed by one-way ANOVA with post-hoc Tukey’s honestly significant difference (HSD). 
Finally, analysis of measurement invariance was conducted as a prerequisite for comparing latent means in creativity domains of K-DOCS among males and females. Testing for measurement invariance required consecutive examination of four nested models with progressively imposed equality constraints: configural, weak, strong, and strict. A more stringent level of measurement invariance (e.g., weak invariance) was retained if imposing additional equality constraints (e.g., equal factor loadings) did not correspond to a significant decrease in data-model fit when compared to fit of a previously retained model (e.g., configural invariance). Model fit was assessed by $\Delta \chi^{2}, \Delta \mathrm{CFI}$, and $\Delta \mathrm{RMSEA}$. Statistically significant results for $\Delta \chi^{2}, \Delta \mathrm{CFI} \geq-.010$, and $\Delta \mathrm{RMSEA} \geq .015$ were interpreted as indicating non-invariance (Chen, 2007).

\section{Results}

\section{Exploratory factor analysis}

The preliminary analysis by Kaiser-Mayer-Olkin's measure $(\mathrm{KMO}=.90)$ and Bartlett's test for sphericity $\left(\chi^{2}(1225)=12653.28, p<.001\right)$ supported that the data is suitable for EFA. Data were treated as ordinal. No missing values were present. The estimation method of Ordinary Least Squares (OLS) with promax rotation was used in a polychoric correlation matrix. The rationale was that OLS is free from an assumption of multivariate normality (Osborne, 2014), feasible for analysis of large models with ordinal data (Lee, Zhang, \& Edwards, 2012), and more accurate in estimation of model's parameters and corresponding standard errors than PAF (Principal Axis Factoring; Coughlin, 2013) and DWLS (Diagonally Weighted Least Squares; Forero, Maydeu-Olivares, \& Gallardo-Pujol, 2009) in a case with ordinal variables.

A number of factors to extract was determined by a set of criteria. First, we relied on a parallel analysis (PA) that is a robust method with high performance (e.g., Fabrigar, 
Wegener, MacCallum, \& Strahan, 1999; Velicer, Eaton, \& Fava, 2000). More concretely, we conducted PA on Pearson's correlation coefficients with both PCA (Principal Component Analysis) and PAF and decided on a number of factors based on $95^{\text {th }}$ percentile value. Second, we accompanied PA with comparison data (CD; Ruscio \& Roche, 2012), Hull methods (Hull-CFI and Hull-CAF; Lorenzo-Seva et al., 2011), and scree-plot test built on the reduced correlation matrix. Results can be seen in Table 1.

Both on empirical and theoretical considerations, we ended with a five-factor structure as most promising. Extraction of the sixth and seventh factors not only did not improve the explained amount of variance but also obscured interpretation. For instance, the sixth factor included only two variables (items 36 and 40) related to solving math puzzles and could have emerged due to the high correlation between these items united by a general context. Thus, it can be seen as an artificial division of a general factor (Lorenzo-Seva et al., 2011). As for the seventh factor, it had moderate loadings on several variables that did not allow for reasonable interpretation.

The matrix of pattern coefficients for the five-factor solution is provided in Table 2. All extracted factors were similar in content to those of previous studies. Five items were dropped due to either low loadings on all factors or comparable cross-loadings on two factors with no adequate interpretation (items 14, 15, 18, 20, and 49). Moreover, items 16 and 22 from the Scholarly factor were incorporated in the Everyday factor because they had higher loadings on the latter and their interpretation under this factor was theoretically permissible. When assigning variables to specific factors, we carefully studied not only the matrix of pattern coefficients but also the matrix of structure coefficients. Analysis of both matrices found no significant contradictions between them. The five-factor structure explained $47 \%$ of the variance in observed variables. Overall, the results of EFA provided preliminary support for H1. 


\section{Confirmatory factor analysis}

The CFA model was specified based on results of EFA. Given the high correlation between items 36 and 40, we added a covariance path between their residuals. In our opinion, such an approach is more theoretically justified than allotting these items to a specific factor. The data contained no missing values. Distribution of variables did not meet the requirement of multivariate normality (according to Henze-Zirkler test; $H Z=1.00, p<.001$ ). All variables were analyzed as if they were continuous. It was shown that if the number of response categories is greater than or equal to five and the threshold values of categories are only moderately skewed, the results for the robust maximum likelihood estimation method has to be comparable to the results obtained with the robust categorical least squares estimation method (Rhemtulla, Brosseau-Liard, \& Savalei, 2012). The sample variance-covariance matrix was analyzed by maximum likelihood estimation with robust standard errors (Satorra \& Bentler, 1994).

The proposed model did not agree well with empirical data: $\chi^{2} \mathrm{SB}(934)=3323.43, p<$ $.001, \mathrm{CFI}=.743, \mathrm{RMSEA}=.071(90 \% \mathrm{CI}=.071-.074), \mathrm{SRMR}=.091$. We carefully analyzed the matrix of standardized residuals and modification indices along with expected parameter changes (EPC) to identify major sources of misfit. As a result, we drew attention to the most significant inconsistencies (see Table 3). In view of the fact that elimination of one discrepancy may lead to the elimination of others, we ensured that each identified inconsistency persisted even after all others were excluded. In other words, we tried to avoid the situation of over-fitting the model to the features of a particular sample. Moreover, all inconsistencies listed in Table 3 were selected on the condition that they could be justified from a theoretical point of view. Interestingly, a similar problem with residual correlations 
was reported in the recent paper on the BICB (Biographical Inventory of Creative Behaviors; Silvia et al., 2020).

The modified model contained seven new parameters and demonstrated better fit to empirical data: $\chi^{2}{ }_{\mathrm{SB}}(927)=2681.92, p<.001, \mathrm{CFI}=.811, \mathrm{RMSEA}=.061(90 \%$ CIs $=.059-$ $.064)$, SRMR $=.087$. Also, the modified model with five correlated factors achieved a better fit than alternative models, including one-factor model (domain-general view), model with five uncorrelated factors (domain-specific view), and model with one general second-order factor (synthesis of domain-general and domain-specific views; see Table 4). We admit that the adopted model is not devoid of some inconsistencies, but, in our opinion, they are much smaller in scope than those already eliminated. A statistically significant result for the $\chi^{2}$ could be explained by the large sample size, model complexity and remaining model inconsistencies. The low values of CFI could appear due to a variety of reasons. First, they are to some extent related to remaining inconsistencies in the model. Second, CFI depends on the number of variables analyzed, albeit to a smaller extent. For large structural models, CFI values tend to decrease, which does not always mean that the model does a poor job (Ding, Velicer, \& Harlow, 1995; Kenny \& McCoach, 2003). According to some methodologists, $\mathrm{CFI}$ is more relevant in the context of exploratory rather than strictly confirmatory analysis (Rigdon, 1996). In the context of CFA, RMSEA is more informative, which corresponded to a satisfactory level of convergence in our study. Finally, contradictions between CFI and RMSEA do not always indicate gross inconsistencies in the model but may be determined by conceptual differences between indices (Lai \& Green, 2016) and depend on the applied method of factor analysis (Xia \& Yang, 2019). In sum, CFA results supported H1.

Given the high consistency in results of EFA and CFA, we combined all data and conducted further psychometric analysis on the entire sample $(N=1011)$. Analysis using the maximum likelihood method with robust errors showed that the model was in acceptable 
agreement with the data: $\chi^{2}{ }_{\mathrm{SB}}(927)=4200.10, p<.001, \mathrm{CFI}=.824, \mathrm{RMSEA}=.059(90 \%$ CIs $=.057-.061)$, SRMR $=.085$.

\section{Reliability analysis}

The results of reliability analysis are presented in Table 5. All K-DOCS factors demonstrated acceptable point estimates for internal consistency with narrow confidence intervals.

A satisfactory level of test-retest reliability was found only for three factors: Scholarly, Performance, and Scientific. Test-retest reliability was low for Everyday factor and had too much variability for Artistic. In this regard, we took a closer look at corresponding effects. For Everyday, a large effect of error term was found while a minor effect was associated with repeated trials. However, the wide confidence intervals for the Artistic factor might indeed correspond to the effect of repeated trials. It means that a satisfactory level of test-retest reliability $(\operatorname{ICC}(\mathrm{A}, 1)=.69)$ was achieved due to high interindividual variability that masked the statistically significant effect of repeated trials. Therefore, Artistic factor is the only one that demonstrated low stability over time. It follows that $\mathrm{H} 2$ received only partial support.

\section{Construct validity}

Results of the correlation analysis are presented in Table 6. All associations were analyzed using the Pearson correlation coefficient because preliminary analysis showed that the data did not violate its assumptions.

In most cases, convergent validity hypotheses were confirmed. In particular, we found moderate positive correlations between the Artistic factor of K-DOCS and the Visual arts ( $r=$ 
$.54, p<.001)$ and Crafts $(r=.30, p<.001)$ subscales of CBI. Additionally, a positive correlation of similar magnitude was obtained between the Performance factor of K-DOCS and CBI Literature $(r=.43, p<.001)$. Equally important evidence in favor of convergent validity was a moderate positive correlation between K-DOCS Artistic factor and aesthetic qualities (i.e. openness; $r=.38, p<.001$ ) as a facet of openness to experience. Although the association of K-DOCS Scholarly factor with curiosity (i.e. intellect) as a facet of openness to experience was relatively weak $(r=.24, p<.001)$, it was nevertheless the highest in comparison with values for other K-DOCS factors. Thus, $\mathrm{H} 3 \mathrm{a}, \mathrm{H} 3 \mathrm{~b}$, and $\mathrm{H} 3 \mathrm{c}$ were fully supported, and H3d was only partially supported.

Evidence on discriminant validity was mixed. While K-DOCS Artistic and Scholarly factors were indeed related only to openness to experience, the corresponding association for Scientific factor was significantly lower in magnitude than, for instance, its negative association with neuroticism $(r=-.19, p<.001)$. In line with our expectations, Performance factor was unrelated to traits of agreeableness $(r=.06, p=.445)$, conscientiousness $(r=.02$, $p=.061)$, and neuroticism $(r=-.01, p=.693)$, but showed a weak positive association with extraversion $(r=.21, p<.001)$. It is worth noting that weak correlations between the Everyday factor and conscientiousness $(r=.15, p<.001)$ and neuroticism $(r=-.23, p<.001)$ were also in agreement with our predictions. However, the hypothesis that conscientiousness would be positively related to the Scientific factor and negatively to the Artistic factor remained unsupported. Thus, $\mathrm{H} 4 \mathrm{c}, \mathrm{H} 4 \mathrm{~d}$, and $\mathrm{H} 4 \mathrm{e}$ were fully confirmed, $\mathrm{H} 4 \mathrm{a}$ was partially confirmed, and $\mathrm{H} 4 \mathrm{~b}$ was incompatible with empirical evidence.

Further, we examined differences in K-DOCS domains among various occupations. First, we divided participants into groups by their professions according to Holland's RIASEC model. Two researchers - the first author and a psychology graduate student of St. Petersburg State University - performed this task independently. Results of coding showed a 
high degree of agreement (Cohen's kappa $(\kappa)=.78, \mathrm{se}=.016)$. All inconsistencies in coding were resolved during a discussion session. Importantly, data from students, housewives, unemployed and retired people, and women on maternity leave were excluded from the analysis prior to coding. Also, we did not consider data of participants who defined their occupation in broad terms (e.g., "specialist," "freelancer") or reported several different occupations (e.g., "accountant and conductor"). Finally, we ended with data from 779 participants (see Table 7).

Before running a one-way ANOVA, we established the homogeneity of variance and checked for outliers. Homogeneity of variance was tested using Levene's test based on median because it is more robust for asymmetric distributions (Brown \& Forsythe, 1974). The assumption of variance homogeneity was satisfied in all cases. All identified outliers were excluded (criterion: Median $\pm 3 \times$ MAD; see for details Leys et al., 2013).

As to the results of ANOVA with post-hoc Tukey's HSD, no significant differences were observed across occupations for Everyday factor (Table 8). Hence, our hypothesis that social type would have higher scores on everyday creativity than other types was not confirmed (H5c). In a similar vein, investigative type did not stand out on K-DOCS Scholarly factor when compared with other occupational types (H5a). However, investigative type outperformed social and conventional types on Scientific factor. Artistic type obtained higher scores on Performance factor than realistic and conventional ones and stood out significantly from all other types on the K-DOCS Artistic factor (H5b). Thus, H5b was fully supported, whereas H5a was partially supported.

In addition, we built a hierarchical regression model to find out significant predictors of K-DOCS factors among Big Five personality traits, occupations, and measures of creative behavior (see Table 9). The preliminary analysis confirmed that all assumptions of hierarchical regression analysis were met. As expected, openness to experience served as a 
major predictor of creative self-assessments across all K-DOCS domains. Extraversion positively predicted the Everyday and Performance factors, whereas neuroticism demonstrated negative associations with the Everyday, Scholarly, and Scientific factors. In general, the entry of occupation types did not improve model fit. The only exception from the rule is the Scientific factor, which was predicted by realistic, investigative, and social types. Although it was unsurprising that CBI Literature served as a statistically significant predictor for Scholarly and Performance factors, we did not expect to obtain a similar result for the Everyday factor. In sum, these results only partially corroborated our hypotheses on construct validity.

\section{Measurement invariance across gender}

Before examining gender differences, we had to establish measurement invariance for the K-DOCS across gender. As can be seen in Table 10, the model with five correlated factors showed an acceptable fit for both males and females. Multigroup CFA was used to verify the configural, metric, scalar, and strict invariance. Given that strict measurement invariance is hard to achieve, we confined to establishing scalar invariance in order to proceed with the latent mean comparison. The results for the full model did not support scalar measurement invariance $(\Delta \mathrm{CFI}>.010)$. After close examination of modification indices $(\mathrm{MI})$ and their expected parameter change (EPC), we relaxed the constraints for the intercept of item 37. The latter resulted in support for partial scalar measurement invariance $(\triangle \mathrm{CFI}=$ $.008, \Delta \mathrm{RMSEA}=.001$; see Table 10 for further details).

After establishment of the partial scalar invariance, we explored the latent mean differences across gender. We constrained the males' group latent means to zero and the latent means of the females' group were freely estimated. We used critical ratio (CR; parameter estimate divided by its standard error) to assess latent mean differences. Effect 
sizes were estimated by Glass' delta (Steinmetz, 2011). It was found that females scored higher than males on Everyday $(\mathrm{CR}=2.12, p=.034$, Glass' $\Delta=.14)$, Scholarly $(\mathrm{CR}=2.62$, $p=.009$, Glass' $\Delta=.19)$, Performance $(\mathrm{CR}=2.58, p=.010$, Glass' $\Delta=.17)$, and Artistic factors $(\mathrm{CR}=6.50, p<.001$, Glass' $\Delta=.59)$. At the same time, males significantly outperformed females on Scientific factor $(\mathrm{CR}=-9.09, p<.001$, Glass' $\Delta=.76)$. Thus, H6a and H6b were fully supported.

\section{Discussion}

The K-DOCS is a relatively new self-report creativity scale. In this regard, the accumulation of empirical evidence on its reliability and validity is strongly needed. In the present study, we investigated the psychometric properties of the K-DOCS on a Russianspeaking population and tested hypotheses concerning its factor structure, test-retest reliability, construct validity, and measurement invariance.

The model with five correlated factors demonstrated the best fit to empirical data. These results are consistent with most previous studies (Awofala \& Fatade, 2015; McKay et al., 2017; Şahin, 2016). Hence, we did not find support for a nine-factor structure similar to that reported in Kandemir and Kaufman (2019), even though our study also relied on the method of parallel analysis. These differences could be due to several reasons. First, we used a group of methods rather than a single one for identifying the number of factors in EFA. This approach allowed us to compare results obtained by different methods and reach a more balanced decision. Second, in contrast to Kandemir and Kaufman, we conducted a parallel analysis based on PCA and not PAF. It is known that PAF - compared to PCA - is more prone to overestimate the number of factors in a case of ordinal variables (Timmerman \& Lorenzo-Seva, 2011). Moreover, parallel analysis tends to overestimate the required number of factors when a large set of variables is analyzed (Van der Eijk \& Rose, 2015) and when a 
sample size is large (Warne \& Larsen, 2014). Interestingly, in our study parallel analysis using PCA suggested extracting five factors, whereas parallel analysis using PAF suggested seven factors. However, extraction of the seventh factor was not justified from a theoretical point of view. The sixth factor, encompassing only two items from a mathematical domain, could have resulted because both items shared similar content ("bloated specifics"; see Cattell $\&$ Tsujioka, 1964). Overall, the described differences between five- and nine-factor structures are most likely due to the functioning nuances of parallel analysis and has little to do with substantial differences in creative self-expression across domains.

Internal consistency reliability for K-DOCS factors ranged from satisfactory to very good, which closely matches the results of previous studies (e.g., Dostál et al., 2017; Kaufman, 2012; McKay et al., 2017). Contrary to expectations, test-retest reliability was lower than reported elsewhere (Awofala \& Fatade, 2015; Kaufman, 2012). The application of different statistical methods such as the Pearson correlation coefficient (relative agreement) and ICC (absolute agreement) cannot explain this discrepancy (Koo \& Li, 2016). Test-retest reliability differed by two coefficients- $\mathrm{ICC}(\mathrm{A}, 1)=.69$ and $r=.77$ - only for Artistic but no other K-DOCS factors. However, it is necessary to take into account the differences in the procedure between the current study and previous ones. First, we conducted test-retest online, whereas previous studies collected data offline. Can we consider results on K-DOCS obtained in online and offline formats to be equivalent? Unfortunately, it is an open question deserving empirical testing. Second, in our study, two measures - test and retest-were performed under contrasting conditions: the first one was conducted on Yandex Toloka under time constraints, whereas the second one was performed via Google Forms without time constraints. Finally, the impact of sampling error cannot be discounted, since only a small group of participants agreed to proceed with test-retest. 
Russian K-DOCS showed good convergent validity. Namely, the Artistic and Performance factors moderately correlated with the comparable subscales of CBI, and almost all K-DOCS factors were to some extent correlated with openness to experience. The latter is not surprising because openness to experience is a well-known predictor of both creative potential and creative achievements (e.g., Feist, 1998; Oleynick et al., 2017; Wolfradt \& Pretz, 2001). Yet it is worth noting that Scientific factor was poorly correlated with openness to experience. Similar results were reported earlier for domains of science and mathematics (see Kaufman, 2012; Silvia et al., 2009). Silvia and colleagues suggested that such a pattern might reflect a stable stereotype that there is no room for creativity in science and mathematics. These stereotypes could emerge from school experiences. For example, it has been repeatedly shown that math teachers have limited conceptions on the role of creativity in mathematics (Bolden, Harries, \& Newton, 2010; but see Leikin, Subotnik, Pitta-Pantazi, Singer, \& Pelczer, 2013, for opposite findings). Consistently, science and math teachers exhibit a stronger tendency toward art bias (Patston, Cropley, Marrone, \& Kaufman, 2018). Consequently, social stereotypes about mathematical abilities and math teachers' implicit theories of creativity could promote in children — and future adults — a shared belief that mathematics and creativity are distinct dimensions having no common ground (Kaufman \& Baer, 2004).

In addition, we suggested that creativity self-ratings in the arts and science would be differentially related to openness and intellect as facets of openness to experience. According to some studies, openness predicts creative achievements in arts, but not in science, and intellect predicts creative achievements in science, but not in arts (Kaufman et al., 2016; Perrine \& Brodersen, 2005). In our results, the Artistic factor was more closely related to openness than to intellect, but the Scholarly factor was equally related to both facets. One possible explanation is that in Russian K-DOCS, the Scholarly factor consists of items related 
to analyzing and writing scientific papers rather than searching for information and designing experiments. In this light, it becomes clear why CBI Literature explained so much variance in the Scholarly factor. Writing scientific articles requires not only specialized knowledge and the ability to locate relevant sources but also strong writing abilities to communicate findings in an understandable and appealing fashion.

The Russian K-DOCS also had acceptable discriminant validity. As predicted, all KDOCS factors were weakly associated with neuroticism, agreeableness, and conscientiousness. Importantly, low correlations were not an effect of the restriction of range. Weak associations between self-reported creativity and neuroticism reinforce previous findings (Kaufman, 2012; McKay et al., 2017; Wolfradt \& Pretz, 2001). Still, K-DOCS Scientific and Everyday factors showed small negative correlations with neuroticism. It might mean that creative self-expression in science and everyday life implies higher emotional stability. Likewise, Silvia et al. (2009) found a weak negative correlation between neuroticism and math-science creativity and between neuroticism and empathicinterpersonal creativity. Next, low correlations between agreeableness and all K-DOCS factors is hardly surprising given that creative persons express their independence and defy the crowd and socially accepted norms (Sternberg, 2018). To quote Torrance's famous "Manifesto for Children," “don't waste energy trying to be well rounded” (Torrance, 1995, p. 364). As for conscientiousness, we expected that it would positively correlate with Scientific factor and negatively with Artistic factor. However, both correlations were close to zero. There are several possible explanations. Conscientiousness sometimes is associated with a suppression effect with creativity, in which some aspects of the factor are positively associated and others are negative associated, leading to the appearance of no strong relationship (Reiter-Palmon, Illies, \& Kobe-Cross, 2009). Further, even though our sample included people actually working in the relevant fields (as opposed to college students), this 
does not mean that their creative metacognition was particularly high (e.g., Kaufman \& Beghetto, 2013). People working in the sciences may rate themselves lower on self-reported creativity because they have seen genuine creative performance in science, whereas people not in science may be using a different comparison point.

Considering construct validity, the present study compared creativity self-ratings in K-DOCS among occupations in Holland's model on a sample of adults. Although Plháková, Dostal, and Záškodná (2015) undertook a similar analysis earlier, their evidence was limited to university students. Studying adult samples is of special interest because it remains largely unexplored to what extent previous findings on student samples (Kandemir \& Kaufman, 2019) can be generalized to a population of adults. In line with our expectations, artistic types received higher scores on Artistic and Performance factors, whereas investigative and realistic types received higher scores on Scientific. The main limitation, however, is that in most cases differences in creativity scores among occupations did not reach the level of statistical significance. In particular, no statistically significant differences were found on the Everyday factor. Surprisingly, artistic type scored higher on the Scholarly factor than investigative type, although the difference was non-significant. As mentioned before, this could reflect the limited scope of Scholarly factor (i.e. literature analysis and writing articles). In total, we showed that K-DOCS construct validity is at least partially generalizable to the population of adults.

Finally, yet importantly, we established a partial measurement invariance of K-DOCS across gender. That allowed us to highlight differences in creative self-assessment between males and females. It appeared that females surpassed males almost in all domains of $\mathrm{K}$ DOCS except for Scientific. In addition, the most prominent differences between groups corresponded to Artistic and Scientific factors, which corroborates and extends previous evidence (Diedrich et al., 2018; Elisondo, 2020; Kaufman, 2006; Kaufman et al., 2010; 
Werner et al., 2014). These patterns, as with the more general findings on mathematics and creativity, could reflect societal expectations. Girls tend to see themselves as having higher abilities in the arts (and lowers in STEM-related areas), which then interacts with motivation and potentially career pathways (Freedman-Doan et al., 2000; Lazarides \& Lauermann, 2019). Thus, that the differences in self-reported creativity generally mirror broad stereotypes may simply be a reflection of these stereotypes, and not evidence supporting their accuracy.

The findings of the study should be considered in light of its limitations. First, when studying the factor structure, we modified the CFA model, which automatically shifted our analysis from the confirmatory approach to the exploratory one. Therefore, the K-DOCS factor structure adopted in this study requires further empirical examination in a confirmatory manner. Second, we encountered difficulties in interpreting the results of test-retest for Artistic factor. More specifically, it is not yet clear to what extent the results were conditioned by specifics of test-retest's procedure or instability of creative self-perception. Further, conflicting results for comparing occupational types could arise because a person's profession did not perfectly correspond to their interests, personality profile, and ability level. In other words, assigning a person to a particular occupation based only on their actual profession could have led to a mixture of different types among themselves. It is highly likely that many people are working in jobs that do not correspond with their passions or personality. To overcome this limitation, it would be necessary to not only use actual occupation but to assign respondents to an "occupational type," based on such indicators as interests, personality, self-beliefs, and others. Finally, this study relied on self-reported measures, and, thus, creativity ratings reflected only the respondents' self-perception on their performance and involvement in various creative activities. In this regard, we agree with Kandemir and Kaufman (2019) that one promising future direction would be to validate K- 
DOCS against objective indicators of creative achievements and performance (see also Reiter-Palmon, Robinson-Morral, Kaufman, \& Santo, 2012).

In summary, the present study contributes to the growing evidence on the psychometric properties of K-DOCS by translating and validating a Russian version of the measure. Online data collection coupled with control for careless responding allowed us to achieve a wide coverage of different demographic groups and high internal validity, while advanced statistical analysis conducted in view of the current psychometric and statistical standards allowed us to take into account and overcome a number of limitations inherent in previous works. Overall, our work supports previous evidence on the reliability and validity of K-DOCS and extends it by demonstrating external validity with respect to occupations and establishing partial measurement invariance across gender. It follows that self-assessment methods, despite all their shortcomings, can indeed provide researchers with valuable information about creativity, and, no less important, while meeting the high psychometric standards. 


\section{References}

Awofala, A. O., \& Fatade, A. O. (2015). Validation of the domains of creativity scale for Nigerian preservice science, technology, and mathematics teachers. Electronic Journal of Research in Educational Psychology, 13(1), 131-150. doi: 10.14204/ejrep.35.14057

Baer, J., \& Kaufman, J. C. (2005). Bridging generality and specificity: The amusement park theoretical (APT) model of creativity. Roeper Review, 27(3), 158-163. doi: $10.1080 / 02783190509554310$

Baer, J., \& Kaufman, J. C. (2017). The Amusement Park Theoretical Model of Creativity: An attempt to bridge the domain specificity/generality gap. In J. C. Kaufman, V. P. Glăveanu, \& J. Baer (Eds.), Cambridge handbook of creativity across domains (pp. 8-17). Cambridge University Press.

Bernaards, C. A., \& Jennrich, R. I. (2005). Gradient projection algorithms and software for arbitrary rotation criteria in factor analysis. Educational and Psychological Measurement, 65(5), 676696. doi: $10.1177 / 0013164404272507$

Bolden, D. S., Harries, T. V., \& Newton, D. P. (2010). Pre-service primary teachers' conceptions of creativity in mathematics. Educational Studies in Mathematics, 73(2), 143-157. doi: $10.1007 / \mathrm{s} 10649-009-9207-\mathrm{z}$

Brown, M. B., \& Forsythe, A. B. (1974). Robust tests for the equality of variances. Journal of the American Statistical Association, 69(346), 364-367.

Cattell, R. B., \& Tsujioka, B. (1964). The importance of factor-trueness and validity, versus homogeneity and orthogonality, in test scales ${ }^{1}$. Educational and Psychological Measurement, 24(1), 3-30. doi: 10.1177/001316446402400101 
Chen, F. F. (2007). Sensitivity of goodness of fit indexes to lack of measurement invariance. Structural Equation Modeling: A Multidisciplinary Journal, 14(3), 464-504. doi: $10.1080 / 10705510701301834$

Christensen, A. P., Cotter, K. N., \& Silvia, P. J. (2019). Reopening openness to experience: A network analysis of four openness to experience inventories. Journal of Personality Assessment, 101(6), 574-588. doi: 10.1080/00223891.2018.1467428

Coughlin K. B. (2013). An analysis of factor extraction strategies: A comparison of the relative strengths of principal axis, ordinary least squares, and maximum likelihood in research contexts that include both categorical and continuous variables [Unpublished doctoral dissertation]. University of South Florida.

DeYoung, C. G., Quilty, L. C., \& Peterson, J. B. (2007). Between facets and domains: 10 aspects of the Big Five. Journal of Personality and Social Psychology, 93(5), 880-896. doi: $10.1037 / 0022-3514.93 .5 .880$

Diedrich, J., Jauk, E., Silvia, P. J., Gredlein, J. M., Neubauer, A. C., \& Benedek, M. (2018). Assessment of real-life creativity: The Inventory of Creative Activities and Achievements (ICAA). Psychology of Aesthetics, Creativity, and the Arts, 12(3), 304-316. doi: 10.1037/aca0000137

Ding, L., Velicer, W. F., \& Harlow, L. L. (1995). Effects of estimation methods, number of indicators per factor, and improper solutions on structural equation modeling fit indices. Structural Equation Modeling: A Multidisciplinary Journal, 2(2), 119-143. doi: $10.1080 / 10705519509540000$

Dupuis, M., Meier, E., \& Cuneo, F. (2019). Detecting computer-generated random responding in questionnaire-based data: A comparison of seven indices. Behavior Research Methods, 51(5), 2228-2237. doi: 10.3758/s 13428-018-1103-y 
Dollinger, S. J. (2003). Need for uniqueness, need for cognition, and creativity. The Journal of Creative Behavior, 37(2), 99-116. doi: 10.1002/j.2162-6057.2003.tb00828.x

Dostál, D., Plháková, A., \& Záškodná, T. (2017). Domain-specific creativity in relation to the level of empathy and systemizing. The Journal of Creative Behavior, 51(3), 225-239. doi: 10.1002/jocb.103

Elisondo, R. C. (2020). Creative Actions Scale: A Spanish scale of creativity in different domains. Journal of Creative Behavior. Advance online publication. doi: 10.1002/jocb.447

Fabrigar, L. R., Wegener, D. T., MacCallum, R. C., \& Strahan, E. J. (1999). Evaluating the use of exploratory factor analysis in psychological research. Psychological Methods, 4(3), 272-299. doi: 10.1037/1082-989X.4.3.272

Feist, G. J. (1998). A meta-analysis of personality in scientific and artistic creativity. Personality and Social Psychology Review, 2(4), 290-309. doi: 10.1207/s15327957pspr0204_5

Fleischer, A., Mead, A. D., \& Huang, J. (2015). Inattentive responding in MTurk and other online samples. Industrial and Organizational Psychology, 8(2), 196-202. doi: 10.1017/iop.2015.25

Forero, C. G., Maydeu-Olivares, A., \& Gallardo-Pujol, D. (2009). Factor analysis with ordinal indicators: A Monte Carlo study comparing DWLS and ULS estimation. Structural Equation Modeling: A Multidisciplinary Journal, 16(4), 625-641. doi: 10.1080/10705510903203573

Freedman-Doan, C., Wigfield, A., Eccles, J. S., Blumenfeld, P., Arbreton, A., \& Harold, R. D. (2000). What am I best at? Grade and gender differences in children's beliefs about ability improvement. Journal of Applied Developmental Psychology, 21(4), 379-402. doi: 10.1016/S0193-3973(00)00046-0

Glăveanu, V. P. (2014). The psychology of creativity: A critical reading. Creativity. Theories Research-Applications, 1, 10-32. doi: 10.15290/ctra.2014.01.01.02 
Holland, J. L. (1985). Making vocational choice: A theory of careers. Englewood Cliffs, NJ: Prentice Hall.

Jauk, E., Benedek, M., \& Neubauer, A. C. (2014). The road to creative achievement: A latent variable model of ability and personality predictors. European Journal of Personality, 28(1), 95-105. doi: 10.1002/per.1941

Kandemir, M. A., \& Kaufman, J. C. (2019). The Kaufman Domains of Creativity Scale: Turkish validation and relationship to academic major. The Journal of Creative Behavior. Advance online publication. doi: 10.1002/jocb.428

Kapoor, H., Reiter-Palmon, R., \& Kaufman, J. C. (2020). Norming the muses: Establishing the psychometric properties of the Kaufman Domains of Creativity Scale (K-DOCS) [Manuscript submitted for publication]. Department of Psychology, Monk Prayogshala.

Kaufman, J. C. (2006). Self-reported differences in creativity by ethnicity and gender. Applied Cognitive Psychology: The Official Journal of the Society for Applied Research in Memory and Cognition, 20(8), 1065-1082. doi: 10.1002/acp.1255

Kaufman, J. C. (2012). Counting the muses: development of the Kaufman domains of creativity scale (K-DOCS). Psychology of Aesthetics, Creativity, and the Arts, 6(4), 298-308. doi: $10.1037 / \mathrm{a} 0029751$

Kaufman, J. C. (2019). Self-assessments of creativity: Not ideal, but better than you think. Psychology of Aesthetics, Creativity, and the Arts, 13(2), 187-192. doi: 10.1037/aca0000217

Kaufman, J. C., \& Baer, J. (2004). Sure, I'm creative_-but not in mathematics!: Self-reported creativity in diverse domains. Empirical Studies of the Arts, 22(2), 143-155. doi: 10.2190/26HQ-VHE8-GTLN-BJJM 
Kaufman, J. C., \& Beghetto, R. A. (2013). In praise of Clark Kent: Creative metacognition and the importance of teaching kids when (not) to be creative. Roeper Review, 35, 155-165. doi: $10.1080 / 02783193.2013 .799413$

Kaufman, J. C., Pumaccahua, T. T., \& Holt, R. E. (2013). Personality and creativity in realistic, investigative, artistic, social, and enterprising college majors. Personality and Individual Differences, 54(8), 913-917. doi: 10.1016/j.paid.2013.01.013

Kaufman, J. C., Waterstreet, M. A., Ailabouni, H. S., Whitcomb, H. J., Roe, A. K., \& Riggs, M. (2010). Personality and self-perceptions of creativity across domains. Imagination, Cognition and Personality, 29(3), 193-209. doi: 10.2190/IC.29.3.c

Kaufman, S. B. (2013). Opening up openness to experience: A four-factor model and relations to creative achievement in the arts and sciences. The Journal of Creative Behavior, 47(4), 233255. doi: 10.1002/jocb.33

Kaufman, S. B., Quilty, L. C., Grazioplene, R. G., Hirsh, J. B., Gray, J. R., Peterson, J. B., \& DeYoung, C. G. (2016). Openness to experience and intellect differentially predict creative achievement in the arts and sciences. Journal of Personality, 84(2), 248-258. doi: 10.1111/jopy.12156

Kelley, K. (2018). MBESS: The MBESS R Package. R package version 4.4.3. Retrieved from https://CRAN.Rproject. org/package=MBESS.

Kelley, K., \& Pornprasertmanit, S. (2016). Confidence intervals for population reliability coefficients: Evaluation of methods, recommendations, and software for composite measures. Psychological Methods, 21(1), 69-92. doi: 10.1037/a0040086 
Kenny, D. A., \& McCoach, D. B. (2003). Effect of the number of variables on measures of fit in structural equation modeling. Structural Equation Modeling: A Multidisciplinary Journal, 10(3), 333-351. doi: 10.1207/S15328007SEM1003_1

Koo, T. K., \& Li, M. Y. (2016). A guideline of selecting and reporting intraclass correlation coefficients for reliability research. Journal of Chiropractic Medicine, 15(2), 155-163. doi: 10.1016/j.jcm.2016.02.012

Korkmaz, S., Goksuluk, D., \& Zararsiz, G. (2014). MVN: An R package for assessing multivariate normality. The R Journal, 6(2), 151-162.

Lai, K., \& Green, S. B. (2016). The problem with having two watches: Assessment of fit when RMSEA and CFI disagree. Multivariate Behavioral Research, 51(2-3), 220-239. doi: 10.1080/00273171.2015.1134306

Lazarides, R., \& Lauermann, F. (2019). Gendered paths into STEM-related and language-related careers: Girls' and boys' motivational beliefs and career plans in math and language arts. Frontiers in Psychology, 10, 1243. doi: 10.3389/fpsyg.2019.01243

Lebedeva, N. M., \& Bushina, E. V. (2015). Influence of personal values and motivation with creative behaviour and attitude to innovations. Psychology in Economics and Management, 7(1), 2635. doi: 10.17150/2225-7845.2015.7(1).26-35

Lebedeva, N., Schwartz, S. H., Van De Vijver, F. J., Plucker, J., \& Bushina, E. (2019). Domains of everyday creativity and personal values. Frontiers in Psychology, 9, Article 2681. doi: 10.3389/fpsyg.2018.02681

Lee, C. T., Zhang, G., \& Edwards, M. C. (2012). Ordinary least squares estimation of parameters in exploratory factor analysis with ordinal data. Multivariate Behavioral Research, 47(2), 314339. doi: 10.1080/00273171.2012.658340 
Leikin, R., Subotnik, R., Pitta-Pantazi, D., Singer, F. M., \& Pelczer, I. (2013). Teachers' views on creativity in mathematics education: an international survey. ZDM, 45(2), 309-324. doi: $10.1007 / \mathrm{s} 11858-012-0472-4$

Leys, C., Ley, C., Klein, O., Bernard, P., \& Licata, L. (2013). Detecting outliers: Do not use standard deviation around the mean, use absolute deviation around the median. Journal of Experimental Social Psychology, 49(4), 764-766. doi: 10.1016/j.jesp.2013.03.013

Lorenzo-Seva, U., Timmerman, M. E., \& Kiers, H. A. (2011). The Hull method for selecting the number of common factors. Multivariate Behavioral Research, 46(2), 340-364. doi: $10.1080 / 00273171.2011 .564527$

Maneesriwongul, W., \& Dixon, J. K. (2004). Instrument translation process: a methods review. Journal of Advanced Nursing, 48(2), 175-186. doi: 10.1111/j.1365-2648.2004.03185.x

Markland, D. (2007). The golden rule is that there are no golden rules: A commentary on Paul Barrett's recommendations for reporting model fit in structural equation modelling. Personality and Individual Differences, 42(5), 851-858. doi: 10.1016/j.paid.2006.09.023

Marsh, H. W., Hau, K. T., \& Wen, Z. (2004). In search of golden rules: Comment on hypothesistesting approaches to setting cutoff values for fit indexes and dangers in overgeneralizing $\mathrm{Hu}$ and Bentler's (1999) findings. Structural Equation Modeling: A Multidisciplinary Journal, 11(3), 320-341. doi: 10.1207/s15328007sem1103_2

McKay, A. S., Karwowski, M., \& Kaufman, J. C. (2017). Measuring the muses: validating the Kaufman Domains of Creativity Scale (K-DOCS). Psychology of Aesthetics, Creativity, and the Arts, 11(2), 216-230. doi: 10.1037/aca0000074 
McKibben, W. B., \& Silvia, P. J. (2017). Evaluating the distorting effects of inattentive responding and social desirability on self-report scales in creativity and the arts. The Journal of Creative Behavior, 51(1), 57-69. doi: 10.1002/jocb.86

McNeish, D. (2018). Thanks coefficient alpha, we'll take it from here. Psychological Methods, 23(3), 412-433. doi: 10.1037/met0000144

Meade, A. W., \& Craig, S. B. (2012). Identifying careless responses in survey data. Psychological Methods, 17(3), 437-455.

Muthén, L. K., \& Muthén, B. O. (2002). How to use a Monte Carlo study to decide on sample size and determine power. Structural Equation Modeling: A Multidisciplinary Journal, 9(4), 599620. doi: 10.1207/S15328007SEM0904_8

Niessen, A. S. M., Meijer, R. R., \& Tendeiro, J. N. (2016). Detecting careless respondents in webbased questionnaires: Which method to use? Journal of Research in Personality, 63, 1-11. doi: 10.1016/j.jrp.2016.04.010

Oleynick, V. C., DeYoung, C. G., Hyde, E., Kaufman, S. B., Beaty, R. E., \& Silvia, P. J. (2017). Openness/intellect: The core of the creative personality. In G. J. Feist, R. Reiter-Palmon, \& J. C. Kaufman (Eds.), Cambridge handbooks in psychology. The Cambridge handbook of creativity and personality research (pp. 9-27). New York, NY: Cambridge University Press. doi: $10.1017 / 9781316228036.002$

Osborne J. W. (2014). Best practices in exploratory factor analysis. Scotts Valley, CA: CreateSpace Independent Publishing.

Patston, T. J., Cropley, D. H., Marrone, R. L., \& Kaufman, J. C. (2018). Teacher implicit beliefs of creativity: Is there an arts bias? Teaching and Teacher Education, 75, 366-374. doi: 10.1016/j.tate.2018.08.001 
Perrine, N. E., \& Brodersen, R. M. (2005). Artistic and scientific creative behavior: Openness and the mediating role of interests. The Journal of Creative Behavior, 39(4), 217-236. doi: 10.1002/j.2162-6057.2005.tb01259.x

Plháková, A., Dostál, D., \& Záškodná, T. (2015). Hollandova typologie profesních zájmů ve vztahu k doménově specifické kreativitě [Holland's typology of vocational interests in relation to domain-specific creativity]. Československá Psychologie, 59, 17-32.

Pornprasertmanit, S., Miller, P., \& Schoemann, A. (2013). simsem: SIMulated Structural Equation Modeling. R package version 0.5-3. Retrieved from http://CRAN.Rproject.org/package $=$ simsem

Puccio, G. J., Miller, B., \& Acar, S. (2019). Differences in creative problem-solving preferences across occupations. The Journal of Creative Behavior, 53(4), 576-592. doi: 10.1002/jocb.241

Qin, S., Nelson, L., McLeod, L., Eremenco, S., \& Coons, S. J. (2019). Assessing test-retest reliability of patient-reported outcome measures using intraclass correlation coefficients: recommendations for selecting and documenting the analytical formula. Quality of Life Research, 28(4), 1029-1033. doi: 10.1007/s11136-018-2076-0

Reiter-Palmon, R., Illies, J. J., \& Kobe-Cross, L. M. (2009). Conscientiousness is not always a good predictor of performance: The case of creativity. The International Journal of Creativity \& Problem Solving, 19, 27-45.

Reiter-Palmon, R., Robinson-Morral, E. J., Kaufman, J. C., \& Santo, J. B. (2012). Evaluation of selfperceptions of creativity: Is it a useful criterion? Creativity Research Journal, 24(2-3), 107114. doi: $10.1080 / 10400419.2012 .676980$

Revelle W. (2019). psych: Procedures for psychological, psychometric, and personality research. R package version 1.9.12. Retrieved from https://CRAN.R-project.org/package=psych. 
Rhemtulla, M., Brosseau-Liard, P. É., \& Savalei, V. (2012). When can categorical variables be treated as continuous? A comparison of robust continuous and categorical SEM estimation methods under suboptimal conditions. Psychological Methods, 17(3), 354-373. doi: $10.1037 / \mathrm{a} 0029315$

Rigdon, E. E. (1996). CFI versus RMSEA: A comparison of two fit indexes for structural equation modeling. Structural Equation Modeling: A Multidisciplinary Journal, 3(4), 369-379. doi: $10.1080 / 10705519609540052$

Rosseel, Y. (2012). lavaan: An R package for structural equation modeling. Journal of Statistical Software, 48(2), 1-36.

Ruscio, J., \& Roche, B. (2012). Determining the number of factors to retain in an exploratory factor analysis using comparison data of known factorial structure. Psychological Assessment, 24(2), 282-292. doi: 10.1037/a0025697

Şahin, F. (2016). Kaufman Alanları Yaratıcılık Ölçeği'nin Türkçeye uyarlanması ve psikometrik özelliklerinin incelenmesi [Adaptation of the Kaufman Domains of Creativity Scale into Turkish and examination of its psychometric properties]. Ilköogretim Online, 15(3), 855-867. doi: 10.17051/io.2016.70479

Satorra, A., \& Bentler, P. M. (1994). Corrections to test statistics and standard errors in covariance structure analysis. In A. von Eye \& C. C. Clogg (Eds.), Latent variable analysis: Applications for developmental research (pp. 399-419). Thousand Oaks, CA: Sage.

Shchebetenko, S., Kalugin, A. Y., Mishkevich, A. M., Soto, C. J., \& John, O. P. (2020). Measurement invariance and sex and age differences of the Big Five Inventory-2: Evidence from the Russian version. Assessment, 27(3), 472-486. doi: 10.1177/1073191119860901 
Sijtsma, K. (2009). On the use, the misuse, and the very limited usefulness of Cronbach's alpha. Psychometrika, 74(1), 107-120. doi: 10.1007/s11336-008-9101-0

Silvia, P. J., Kaufman, J. C., \& Pretz, J. E. (2009). Is creativity domain-specific? Latent class models of creative accomplishments and creative self-descriptions. Psychology of Aesthetics, Creativity, and the Arts, 3(3), 139-148. doi: 10.1037/a0014940

Silvia, P. J., \& Nusbaum, E. C. (2012). What's your major? College majors as markers of creativity. The International Journal of Creativity and Problem Solving, 22(2), 31-43.

Silvia, P., Rodriguez, R., Beaty, R., Frith, E., Kaufman, J. C., Loprinzi, P., \& Reiter-Palmon, R. (2020). Measuring everyday creativity: A Rasch model analysis of the Biographical Inventory of Creative Behaviors (BICB) scale. PsyArXiv. doi: 10.31234/osf.io/3wq7c

Silvia, P. J., Wigert, B., Reiter-Palmon, R., \& Kaufman, J. C. (2012). Assessing creativity with selfreport scales: A review and empirical evaluation. Psychology of Aesthetics, Creativity, and the Arts, 6(1), 19-34. doi: 10.1037/a0024071

Snyder, H. T., Hammond, J. A., Grohman, M. G., \& Katz-Buonincontro, J. (2019). Creativity measurement in undergraduate students from 1984-2013: A systematic review. Psychology of Aesthetics, Creativity, and the Arts, 13(2), 133-143. doi: 10.1037/aca0000228

Soto, C. J., \& John, O. P. (2017). The next Big Five Inventory (BFI-2): Developing and assessing a hierarchical model with 15 facets to enhance bandwidth, fidelity, and predictive power. Journal of Personality and Social Psychology, 113(1), 117-143. doi: 10.1037/pspp0000096

Steinmetz, H. (2011). Estimation and comparison of latent means across cultures. In E. Davidov, P. Schmidt, \& J. Billiet (Eds.), Cross-cultural analysis: Methods and applications (pp. 85-116). New York: Routledge. 
Sternberg, R. J. (2018). A triangular theory of creativity. Psychology of Aesthetics, Creativity, and the Arts, 12, 50-67. doi: 10.1037/aca0000095

Tan, C. S., Tan, S. A., Cheng, S. M., Hashim, I. H. M., \& Ong, A. W. H. (2019). Development and preliminary validation of the 20-item Kaufman Domains of Creativity Scale for use with Malaysian populations. Current Psychology. Advance online publication. doi: $10.1007 / \mathrm{s} 12144-019-0124-8$

Teo, T., \& Fan, X. (2013). Coefficient alpha and beyond: Issues and alternatives for educational research. The Asia-Pacific Education Researcher, 22(2), 209-213. doi: 10.1007/s40299-013$0075-\mathrm{z}$

Timmerman, M. E., \& Lorenzo-Seva, U. (2011). Dimensionality assessment of ordered polytomous items with parallel analysis. Psychological Methods, 16(2), 209-220. doi: 10.1037/a0023353

Torrance E. P. (1995). Why fly? A philosophy of creativity. New Jersey: Ablex Publishing Corporation.

Tu, C., \& Fan, F. (2015). Domain specificity of creativity: Conception and measurement. Advances in Psychology, 11, 648-656. doi: 10.12677/ap.2015.511084

Van der Eijk, C., \& Rose, J. (2015). Risky business: factor analysis of survey data-assessing the probability of incorrect dimensionalisation. PLOS ONE, 10(3), Article e0118900. doi: 10.1371/journal.pone. 0118900

Velicer, W. F., Eaton, C. A., \& Fava, J. L. (2000). Construct explication through factor or component analysis: A review and evaluation of alternative procedures for determining the number of factors or components. In R. D. Goffin, \& E. Helmes (Eds.), Problems and solutions in human assessment: Honoring Douglas Jackson at seventy (pp. 41-71). Boston, MA: Kluwer. 
Warne, R. T., \& Larsen, R. (2014). Evaluating a proposed modification of the Guttman rule for determining the number of factors in an exploratory factor analysis. Psychological Test and Assessment Modeling, 56, 104-123.

Werner, C. H., Tang, M., Kruse, J., Kaufman, J. C., \& Spörrle, M. (2014). The Chinese version of the Revised Creativity Domain Questionnaire (CDQ-R): First evidence for its factorial validity and systematic association with the Big Five. The Journal of Creative Behavior, 48(4), 254-275. doi: 10.1002/jocb.51

Wolfradt, U., \& Pretz, J. E. (2001). Individual differences in creativity: Personality, story writing, and hobbies. European Journal of Personality, 15(4), 297-310. doi: 10.1002/per.409

Xia, Y., \& Yang, Y. (2019). RMSEA, CFI, and TLI in structural equation modeling with ordered categorical data: The story they tell depends on the estimation methods. Behavior Research Methods, 5l(1), 409-428. doi: 10.3758/s13428-018-1055-2

Zaki, R., Bulgiba, A., Nordin, N., \& Ismail, N. A. (2013). A systematic review of statistical methods used to test for reliability of medical instruments measuring continuous variables. Iranian Journal of Basic Medical Sciences, 16(6), 803-807. 
Table 1

Number of factors to extract in EFA

\begin{tabular}{lc}
\hline Criterion & Number of factors \\
\hline Parallel Analysis (PCA) & 5 \\
Parallel Analysis (PFA) & 7 \\
Parallel Analysis (CD) & $6-7$ \\
Hull-CFI & 1 \\
Hull-CAF & 5 \\
Scree-plot test & 5 \\
\hline
\end{tabular}

Note PCA $=$ principal component analysis; $\mathrm{PAF}=$ principal axis factoring; $\mathrm{CD}=$ comparison data; $\mathrm{CFI}=$ comparative fit index; $\mathrm{CAF}=$ common part accounted for. 
Table 2

Exploratory factor analysis for $K-D O C S$

\begin{tabular}{|c|c|c|c|c|c|c|}
\hline \multirow[t]{2}{*}{ Items } & \multicolumn{5}{|c|}{ Pattern coefficients } & \multirow[b]{2}{*}{$h^{2}$} \\
\hline & F1 & F2 & F3 & F4 & F5 & \\
\hline Item 1 & .459 & -.015 & -.012 & .010 & .195 & .30 \\
\hline Item 2 & .723 & .042 & -.034 & -.133 & -.028 & .54 \\
\hline Item 3 & .632 & .043 & .069 & .027 & -.029 & .43 \\
\hline Item 4 & .581 & .042 & -.182 & .127 & .072 & .40 \\
\hline Item 5 & .659 & -.128 & -.139 & -.070 & .114 & .42 \\
\hline Item 6 & .773 & -.051 & -.074 & .088 & -.006 & .57 \\
\hline Item 7 & .756 & .021 & .152 & .003 & -.072 & .60 \\
\hline Item 8 & .543 & .173 & -.131 & .172 & -.041 & .41 \\
\hline Item 9 & .630 & -.073 & .003 & .000 & .089 & .41 \\
\hline Item 10 & .595 & .070 & .092 & -.062 & -.134 & .37 \\
\hline Item 11 & .504 & .022 & .275 & .037 & -.148 & .32 \\
\hline Item 12 & -.107 & .521 & .438 & .081 & .149 & .53 \\
\hline Item 13 & .027 & .442 & .394 & -.109 & .170 & .46 \\
\hline Item 16 & .624 & .155 & -.028 & .054 & .019 & .50 \\
\hline Item 17 & .181 & .538 & .114 & .099 & .199 & .53 \\
\hline Item 19 & .150 & .507 & .102 & -.117 & .277 & .50 \\
\hline Item 21 & .218 & .534 & .163 & .097 & .073 & .51 \\
\hline Item 22 & .692 & .011 & .129 & .041 & -.001 & .54 \\
\hline Item 23 & -.010 & .250 & .951 & -.140 & -.112 & .82 \\
\hline Item 24 & .046 & .152 & .947 & -.060 & -.154 & .78 \\
\hline Item 25 & .061 & .233 & .855 & -.157 & -.070 & .71 \\
\hline Item 26 & -.045 & .102 & .983 & -.065 & -.116 & .83 \\
\hline Item 27 & .004 & -.140 & .551 & .092 & .073 & .41 \\
\hline Item 28 & .093 & -.040 & .527 & .099 & .085 & .40 \\
\hline Item 29 & .090 & .016 & .439 & -.058 & .059 & .24 \\
\hline Item 30 & -.053 & .123 & .897 & -.054 & -.164 & .66 \\
\hline Item 31 & -.038 & -.112 & .697 & .121 & -.061 & .51 \\
\hline Item 32 & .005 & .087 & .644 & .039 & -.035 & .42 \\
\hline Item 33 & -.016 & -.133 & .163 & .572 & .278 & .63 \\
\hline Item 34 & .286 & .008 & -.182 & .478 & -.105 & .29 \\
\hline Item 35 & -.166 & .173 & .236 & .718 & -.222 & .60 \\
\hline Item 36 & -.122 & .476 & -.270 & .663 & -.082 & .56 \\
\hline Item 37 & .157 & -.065 & -.086 & .751 & -.021 & .57 \\
\hline Item 38 & .128 & -.071 & .092 & .783 & -.066 & .67 \\
\hline Item 39 & .136 & .306 & .066 & .458 & .053 & .39 \\
\hline Item 40 & -.194 & .491 & -.240 & .695 & -.083 & .60 \\
\hline Item 41 & -.063 & -.139 & .260 & .610 & .167 & .67 \\
\hline Item 42 & -.145 & -.022 & .275 & .108 & .578 & .59 \\
\hline Item 43 & -.212 & -.044 & .246 & .175 & .613 & .65 \\
\hline Item 44 & -.011 & .134 & -.184 & -.083 & .531 & .22 \\
\hline Item 45 & .139 & .040 & .113 & .002 & .532 & .44 \\
\hline Item 46 & .121 & .025 & .114 & .053 & .511 & .42 \\
\hline Item 47 & -.203 & -.027 & .229 & .313 & .459 & .54 \\
\hline Item 48 & .149 & .219 & -.139 & -.179 & .668 & .52 \\
\hline
\end{tabular}




\begin{tabular}{lcccccc} 
Item 50 & .028 & .270 & -.142 & -.215 & $\mathbf{. 6 4 8}$ & .45 \\
\hline Eigenvalues & 5.78 & 2.38 & 7.20 & 4.21 & 3.87 & \\
\% Variance & 12.08 & 5.30 & 16.00 & 9.40 & 7.10 & \\
F1: Everyday & 1 & & & & & \\
F2: Scholarly & .14 & 1 & & & & \\
F3: Performance & .29 & .07 & 1 & & & \\
F4: Scientific & .54 & .32 & .22 & 1 & & \\
F5: Artistic & .01 & .41 & -.08 & .01 & 1 & \\
\hline
\end{tabular}

Note. Pattern coefficients higher or equal to .40 are given in bold. Provided values of pattern coefficients were calculated for a model that excludes items 14, 15, 18, 20, and 49. The full EFA results with item wordings are available on the OSF: https://osf.io/g5bk4/?view_only=6d1905355d6d429a8be399e0784b7756. 
Table 3

Modification indices and standardized residuals for CFA model

\begin{tabular}{ccccl}
\hline Parameter & MI & SEPC & SR & Theoretical justification \\
\hline IT23 IT25 & 146.81 & .767 & 6.14 & Items about creating verses \\
IT26 IT30 & 92.45 & .500 & 6.29 & Items about writing songs \\
IT27 IT31 & 108.62 & .475 & 8.09 & Items about musical performance \\
IT33 IT41 & 195.00 & .728 & 7.15 & Items about crafts \\
IT37 IT38 & 135.10 & .915 & 6.06 & Items about working with mechanisms \\
IT42 IT43 & 58.64 & .459 & 5.16 & Items about drawing \\
IT50 IT48 & 84.51 & .442 & 8.59 & Items about aesthetic experience \\
\hline
\end{tabular}

Note. Model parameters are designated by items number (e.g., IT23 means "Item 23") and by their relationship (" " means covariance). However, "IT23" refers not to the Item 23 but to its residual. The same is true for all items presented in this table. $\mathrm{MI}=$ modification indices; $\mathrm{SEPC}=$ standardized expected parameter change; $\mathrm{SR}=$ standardized residuals. 
Table 4

Global-fit parameters for alternative CFA models of K-DOCS

\begin{tabular}{lccccc}
\hline Model & $\boldsymbol{\chi}^{2}$ SB & $\boldsymbol{d} \boldsymbol{f}$ & CFI & RMSEA [90\% CIs] & SRMR \\
\hline One factor & 4801.90 & 937 & .584 & $.090[.088, .093]$ & .128 \\
Five uncorrelated factors & 3162.10 & 937 & .761 & $.069[.066, .071]$ & .162 \\
Five correlated factors & 2681.92 & 927 & .811 & $.061[.059, .064]$ & .087 \\
Five factors and one second-order factor & 2730.58 & 932 & .807 & $.062[.059, .064]$ & .092 \\
\hline
\end{tabular}

Note. $\chi_{\mathrm{SB}}^{2}=$ Satorra-Bentler chi-square; $d f=$ degrees of freedom; CFI $=$ comparative fit index; RMSEA = root mean square error of approximation; CIs = confidence intervals; SRMR = standardized root mean square residual. 
Table 5

Reliability estimates for K-DOCS factors

\begin{tabular}{lccc}
\hline Subscale & Internal consistency reliability & & Test-retest reliability \\
\cline { 2 - 2 } & $\omega_{\mathrm{t}}[95 \% \mathrm{CIs}]$ & & $\mathrm{ICC}(\mathrm{A}, 1)[95 \% \mathrm{CIs}]$ \\
\hline Everyday & $.90[.89, .91]$ & $.52[.39, .64]$ \\
Scholarly & $.83[.81, .85]$ & $.62[.50, .71]$ \\
Performative & $.84[.83, .85]$ & $.82[.75, .87]$ \\
Scientific & $.72[.69, .75]$ & $.77[.69, .83]$ \\
Artistic & $.73[.71, .75]$ & & $.69[.34, .83]$ \\
\hline
\end{tabular}

Note. In all cases, internal consistency reliability was estimated based on polychoric correlation coefficients. Internal consistency for Performance, Scientific, and Artistic factors were computed by the $\omega_{\mathrm{B}}$ formula (see Teo $\&$ Fan, 2013) because these factors had correlated residuals. CIs $=$ confidence intervals; ICC $=$ intra-class correlation coefficient; $\mathrm{A}=$ absolute agreement. 
Table 6

Relationship of CBI and Big Five with domains of K-DOCS

\begin{tabular}{lccccc}
\hline Variables & $\begin{array}{c}\text { K-DOCS: } \\
\text { Everyday }\end{array}$ & $\begin{array}{c}\text { K-DOCS: } \\
\text { Scholarly }\end{array}$ & $\begin{array}{c}\text { K-DOCS: } \\
\text { Performance }\end{array}$ & $\begin{array}{c}\text { K-DOCS: } \\
\text { Scientific }\end{array}$ & $\begin{array}{c}\text { K-DOCS: } \\
\text { Artistic }\end{array}$ \\
\hline CBI: Visual Arts & $\mathbf{. 1 3}[.07, .19]$ & $\mathbf{. 2 1}[.15, .27]$ & $\mathbf{. 2 4}[.19, .29]$ & $\mathbf{. 1 3}[.07, .18]$ & $\mathbf{. 5 4} \dagger[.50, .58]$ \\
CBI: Literature & $\mathbf{. 2 1}[.15, .26]$ & $\mathbf{. 4 2}[.37, .46]$ & $\mathbf{. 4 3} \dagger[.39, .48]$ & $.04[-.01, .10]$ & $\mathbf{. 2 3}[.18, .29]$ \\
CBI: Craft & $\mathbf{. 1 5}[.10, .21]$ & $\mathbf{. 1 0}[.04, .16]$ & $\mathbf{. 1 7} \dagger[.10, .23]$ & $\mathbf{. 2 1}[.16, .28]$ & $\mathbf{. 3 0} \dagger[.26, .35]$ \\
Extraversion & $\mathbf{. 3 1}[.25, .38]$ & $\mathbf{. 1 1}[.05, .17]$ & $\mathbf{. 2 1} \dagger[.14, .27]$ & $\mathbf{. 1 1}[.04, .16]$ & $.06[.00, .11]$ \\
Agreeableness & $\mathbf{. 0 9}[.02, .16]$ & $.00[-.06, .05]$ & $.06[-.01, .11]$ & $-.04[-.11, .01]$ & $\mathbf{. 0 9}[.03, .14]$ \\
Conscientiousness & $\mathbf{. 1 5}[.08, .23]$ & $.04[-.03, .10]$ & $.02[-.05, .09]$ & $.04 \dagger[-.03, .09]$ & $.02 \dagger[-.04, .08]$ \\
Neuroticism & $\mathbf{. . 2 3}[-.29,-.18]$ & $\mathbf{. . 0 7}[-.13,-.01]$ & $-.01[-.07, .05]$ & $\mathbf{- . 1 9}[-.26,-.14]$ & $.01[-.05, .07]$ \\
Openness to & $\mathbf{. 1 9}[.13, .24]$ & $\mathbf{. 2 7}[.22, .32]$ & $\mathbf{. 2 4}[.18, .29]$ & $\mathbf{. 1 0}[.04, .16]$ & $\mathbf{. 2 8}[.22, .33]$ \\
experience & & & & & \\
$\quad$ Curiosity & $\mathbf{. 1 5}[.10, .21]$ & $\mathbf{. 2 4} \dagger[.18, .29]$ & $\mathbf{. 1 4}[.08, .21]$ & $\mathbf{. 1 3}[.06, .18]$ & $\mathbf{. 1 2}[.07, .18]$ \\
$\quad$ Aesthetic qualities & $\mathbf{. 1 0}[.04, .16]$ & $\mathbf{. 2 5}[.20, .31]$ & $\mathbf{. 2 6}[.20, .31]$ & $-.05[-.11, .01]$ & $\mathbf{. 3 8} \dagger[.33, .43]$ \\
\hline
\end{tabular}

Note. All correlations are Pearson product-moment correlation coefficients. 95\% confidence intervals are provided in brackets. Statistically significant correlations are highlighted in bold ( $p<.05$ after Holm's correction). Onetailed tests are marked by $\uparrow$. K-DOCS = Kaufman's Domain of Creativity Scale; CBI = Creative Behavior Inventory. 
Table 7

Occupations in RIASEC model

\begin{tabular}{|c|c|c|}
\hline Professional type & $N$ & Examples from our dataset \\
\hline Realistic & 206 & $\begin{array}{l}\text { Driver, engineer, operator, security guard, cook, } \\
\text { worker, locksmith, builder, technician, electrician }\end{array}$ \\
\hline Investigative & 70 & $\begin{array}{l}\text { Analyst, biologist, biochemist, design engineer, art } \\
\text { critic, historian, philologist, chemist }\end{array}$ \\
\hline Artistic & 40 & $\begin{array}{l}\text { Artist, architect, web designer, decorator, designer, } \\
\text { musician, hairdresser, writer, photographer }\end{array}$ \\
\hline Social & 122 & $\begin{array}{l}\text { Educator, doctor, instructor, consultant, nurse, } \\
\text { teacher, psychologist, social worker }\end{array}$ \\
\hline Enterprising & 164 & $\begin{array}{l}\text { Soldier, journalist, copywriter, manager, head of a } \\
\text { department, entrepreneur, manager, economist }\end{array}$ \\
\hline Conventional & 177 & $\begin{array}{l}\text { Administrator, accountant, inspector, cashier, } \\
\text { storekeeper, merchandiser, financier, lawyer }\end{array}$ \\
\hline
\end{tabular}




\section{Table 8}

Means comparison for creative domains based on RIASEC model

\begin{tabular}{lcccccc}
\hline K-DOCS & Realistic & Investigative & Artistic & Social & Enterprising & Conventional \\
\hline Everyday & 3.58 & 3.56 & 3.82 & 3.75 & 3.69 & 3.62 \\
Scholarly & $3.02^{\mathrm{A}, \mathrm{S}, \mathrm{E}}$ & 3.29 & $3.50^{\mathrm{R}}$ & $3.39^{\mathrm{R}}$ & $3.40^{\mathrm{R}}$ & 3.19 \\
Performance & $2.61^{\mathrm{A}, \mathrm{S}}$ & $2.84^{\mathrm{R}}$ & $3.18^{\mathrm{R}, \mathrm{C}}$ & $2.93^{\mathrm{R}}$ & 2.81 & $2.66^{\mathrm{A}}$ \\
Scientific & $2.88^{\mathrm{S}}$ & $2.99^{\mathrm{S}, \mathrm{C}}$ & $2.71^{\mathrm{A}}$ & $2.40^{\mathrm{R}, \mathrm{I}, \mathrm{E}}$ & $2.70^{\mathrm{S}}$ & $2.65^{\mathrm{I}}$ \\
Artistic & $3.32^{\mathrm{A}, \mathrm{S}, \mathrm{E}}$ & $3.61^{\mathrm{A}}$ & $4.28^{\mathrm{R}, \mathrm{I}, \mathrm{E}, \mathrm{C}}$ & $3.61^{\mathrm{R}, \mathrm{A}}$ & $3.61^{\mathrm{R}, \mathrm{A}}$ & $3.51^{\mathrm{A}}$ \\
\hline
\end{tabular}

${ }^{\mathrm{R}}$ Mean significantly differs from realistic $(p<.05) .{ }^{\mathrm{I}}$ Mean significantly differs from investigative $(p<.05) .{ }^{\mathrm{A}}$ Mean significantly differs from artistic $(p<.05)$. ${ }^{\mathrm{S}}$ Mean significantly differs from social $(p<.05)$. ${ }^{\mathrm{E}}$ Mean significantly differs from enterprising $(p<.05) .{ }^{\mathrm{C}}$ Mean significantly differs from conventional $(p<.05)$. 
Table 9

Summary of hierarchical linear regression among K-DOCS factors and other variables

\begin{tabular}{|c|c|c|c|c|c|c|c|c|c|c|c|c|c|c|c|}
\hline \multirow[t]{2}{*}{ Predictors } & \multicolumn{3}{|c|}{ K-DOCS: Everyday } & \multicolumn{3}{|c|}{ K-DOCS: Scholarly } & \multicolumn{3}{|c|}{ K-DOCS: Performance } & \multicolumn{3}{|c|}{ K-DOCS: Scientific } & \multicolumn{3}{|c|}{ K-DOCS: Artistic } \\
\hline & Step 1 & Step 2 & Step 3 & Step 1 & Step 2 & Step 3 & Step 1 & Step 2 & Step 3 & Step 1 & Step 2 & Step 3 & Step 1 & Step 2 & Step 3 \\
\hline Agreeableness & $-0.12^{*}$ & $-0.12^{*}$ & -0.10 & $-0.12^{* * *}$ & $-0.11^{* * *}$ & $-0.08^{* *}$ & -0.07 & -0.06 & 0.02 & $-0.20^{* * *}$ & $-0.20^{\text {*** }}$ & $-0.20^{* * *}$ & -0.04 & -0.02 & 0.02 \\
\hline Conscientiousness & -0.08 & -0.08 & -0.07 & $-0.07^{* *}$ & $-0.08^{* *}$ & $-0.05^{*}$ & $-0.29^{* * *}$ & $-0.29^{* * *}$ & $-0.21^{* * *}$ & -0.003 & 0.02 & 0.01 & $-0.18^{* * *}$ & $-0.18^{* * *}$ & $-0.15^{\text {*** }}$ \\
\hline Extraversion & $0.23^{* * *}$ & $0.23^{* * *}$ & $0.21^{* * * *}$ & 0.03 & 0.03 & 0.003 & $0.30^{* * *}$ & $0.31^{* * *}$ & $0.25^{* * *}$ & -0.01 & -0.01 & -0.02 & -0.05 & -0.04 & -0.03 \\
\hline Neuroticism & $-0.19^{* * *}$ & $-0.19^{* * *}$ & $-0.18^{* * *}$ & $-0.07^{* * * *}$ & $-0.07^{* * *}$ & $-0.07^{* * *}$ & 0.01 & 0.01 & 0.02 & $-0.23^{* * * *}$ & $-0.23^{* * * *}$ & $-0.20^{* * * *}$ & $-0.09^{* *}$ & $-0.08^{* *}$ & -0.04 \\
\hline Openness & $0.24^{* * *}$ & $0.23^{* * *}$ & $0.19^{* * *}$ & $0.24^{* * *}$ & $0.24^{* * *}$ & $0.18^{* * * *}$ & $0.33^{* * *}$ & $0.30^{* * *}$ & $0.12^{*}$ & $0.22^{\text {**** }}$ & $0.21^{* * * *}$ & $0.19^{* * * *}$ & $0.42^{* * * *}$ & $0.39^{* * * *}$ & $0.25^{* * *}$ \\
\hline Realistic & & -0.68 & -0.43 & & $-1.06^{* * *}$ & -0.61 & & -0.84 & 0.38 & & $2.06^{* *}$ & $1.94^{* *}$ & & $-1.91^{* * *}$ & $-1.37^{*}$ \\
\hline Investigative & & -0.89 & -0.64 & & -0.04 & 0.25 & & 0.96 & 1.76 & & $2.91^{* *}$ & $3.07^{* *}$ & & -0.13 & 0.12 \\
\hline Artistic & & 1.27 & 1.10 & & 0.21 & 0.58 & & $3.27^{*}$ & $3.45^{*}$ & & -0.46 & -1.62 & & $3.74^{* * *}$ & 1.67 \\
\hline Social & & 1.60 & 1.33 & & $0.88^{*}$ & 0.56 & & $2.48^{*}$ & 1.61 & & $-2.16^{* * *}$ & $-2.32^{* *}$ & & 0.58 & 0.28 \\
\hline Enterprising & & 0.31 & 0.22 & & 0.59 & 0.45 & & 0.99 & 0.61 & & -0.10 & -0.08 & & 0.19 & 0.05 \\
\hline CBI: Crafts & & & 0.21 & & & -0.15 & & & -0.15 & & & $0.84^{* * * *}$ & & & $0.28^{*}$ \\
\hline CBI: Literature & & & $0.33^{* * *}$ & & & $0.55^{* * *}$ & & & $1.34^{* * *}$ & & & -0.10 & & & 0.08 \\
\hline CBI: Visual arts & & & -0.001 & & & 0.001 & & & 0.26 & & & 0.03 & & & $1.03^{* * * *}$ \\
\hline Adj. $R^{2}$ & .13 & .14 & .15 & .12 & .15 & .25 & .09 & .10 & .23 & .07 & .11 & .14 & .13 & .16 & .35 \\
\hline$\Delta \mathrm{R}^{2}$ & & .01 & .01 & & .03 & .10 & & .01 & .13 & & .04 & .03 & & .03 & .19 \\
\hline
\end{tabular}

Note. All coefficients are unstandardized betas. RIASEC was introduced as a dummy variable with conventional type as a reference category.

${ }^{*} p<.05 .{ }^{* *} p<.01 .{ }^{* * *} p<.001$. 
Table 10

K-DOCS measurement invariance across gender

\begin{tabular}{|c|c|c|c|c|c|c|c|c|}
\hline & $\chi^{2} \mathrm{SB}$ & $d f$ & $p$ & $\Delta \chi^{2} \mathrm{SB}^{\mathrm{a}}$ & CFI & $\Delta \mathrm{CFI}$ & RMSEA & $\triangle \mathrm{RMSEA}$ \\
\hline CFA males $\left(n_{1}=462\right)$ & 2427.53 & 927 & $<.001$ & & .820 & & .064 & \\
\hline CFA females $\left(n_{2}=549\right)$ & 2740.62 & 927 & $<.001$ & & .816 & & .064 & \\
\hline \multicolumn{9}{|l|}{ Full invariance } \\
\hline M1: configural invariance & 5167.34 & 1854 & $<.001$ & & .818 & & .064 & \\
\hline M2: metric invariance & 5224.42 & 1894 & $<.001$ & $61.12^{*}$ & .817 & .001 & .063 & .001 \\
\hline M3: scalar invariance & 5516.18 & 1934 & $<.001$ & $543.84^{* * *}$ & .806 & .011 & .065 & .001 \\
\hline M4: strict invariance & 5631.58 & 1979 & $<.001$ & $113.09^{* * *}$ & .792 & .014 & .067 & .002 \\
\hline \multicolumn{9}{|l|}{ Partial invariance } \\
\hline M1: configural invariance & 5167.34 & 1854 & $<.001$ & & .818 & & .064 & \\
\hline M2: metric invariance & 5224.42 & 1894 & $<.001$ & $61.12^{*}$ & .817 & .001 & .063 & .001 \\
\hline M3: scalar invariance & 5459.79 & 1933 & $<.001$ & $368.54^{* * *}$ & .809 & .008 & .064 & .001 \\
\hline M4: strict invariance & 5575.62 & 1978 & $<.001$ & $113.83^{* * *}$ & .805 & .013 & .064 & \\
\hline
\end{tabular}

Note. Partial measurement invariance was examined for a model with unconstrained intercept for item $37 . \chi^{2} \mathrm{SB}=$ Satorra-Bentler chi-square; $d f=$ degrees of freedom; CFI = comparative fit index; RMSEA = root mean square error of approximation; $\mathrm{CIs}=$ confidence intervals.

a $\Delta \chi^{2} \mathrm{SB}$ was calculated as $\left(\mathrm{SB}_{0} \times \mathrm{C}_{0}-\mathrm{SB}_{1} \times \mathrm{C}_{1}\right) / \mathrm{CD}$, where $\mathrm{SB}_{0}=$ Satorra-Bentler chi-square for the null model, $\mathrm{SB}_{1}=$ Satorra-Bentler chi-square for the alternative model, $\mathrm{C}_{0}=$ scaling correction factor for null model, $\mathrm{C}_{1}=$ scaling correction factor for alternative model, $\mathrm{CD}=$ difference test scaling correction. 